2. Botta L, Russo V, Savini C, Buttazzi K, Pacini D, Lovato L, et al. Endovascular treatment for acute traumatic transection of the descending aorta: focus on operative timing and left subclavian artery management. J Thorac Cardiovasc Surg. 2008;136: 1558-63.

3. Pacini D, Angeli E, Fattori R, Lovato L, Rocchi G, Di Marco L, et al. Traumatic rupture of the thoracic aorta: ten years of delayed management. J Thorac Cardiavasc Surg. 2005;129:880-4.

4. Pate JW, Fabian TC, Walker W. Traumatic rupture of the aortic isthmus: an emergency? World J Surg. 1995;19:119-26.

5. Fattori R, Russo V, Lovato L, Di Bartolomeo R. Optimal management of traumatic aortic injury. Eur J Vasc Endovasc Surg. 2009;37:8-14.

doi:10.1016/j.jtcvs.2009.05.008

\section{MANAGEMENT OF \\ TRAUMATIC \\ MANUBRIOSTERNAL DISLOCATION IN CHILDREN}

\section{To the Editor:}

We read with great interest the article by Irani and colleagues, ${ }^{1}$ highlighting the consequences (chronic pain, periarticular calcification with ankylosis, and significant deformity of the chest wall) of conservative management of sternal fractures in adult patients that may necessitate a more extensive procedure at a later date. Our interest has further increased in the article because we recently faced a dilemma regarding the "ideal acute management" of a child with traumatic manubriosternal dislocation (TMSD). We have performed an extensive literature search for the same and found conflicting reports. Wada and colleagues ${ }^{2}$ support conservative management in children with TMSD as they argue that the joint remodels with time, whereas Nijs and Broos $^{3}$ operated on a child similar to ours. We decided to operate on our patient with a view to provide symptomatic relief and prevent chronic deformity.

Our patient is an 11-year-old girl who presented with pain and a "clicking sensation" in her chest wall 4 days after a fall on a flexed neck while on a trampoline. She was asymptomatic for 2 days before pain developed. The lateral chest radiograph showed a posterior dislocation of the body of the sternum (Figure 1). This is the uncommon variety of TMSD (type 1). ${ }^{4}$ There were no other injuries.

The patient underwent operation via a $2.5-\mathrm{cm}$ transverse incision over the manubriosternal joint. The hematoma was evacuated, and the anterior periosteum over the joint was opened. The sternum was then resutured to the manubrium with continuous 1 Pro- lene (Ethicon, Inc, Somerville, NJ) suture. The joint was stabilized. Her postoperative chest radiograph showed that there was still some posterior subluxation of the sternal body; however, at the 8-week follow-up visit she was asymptomatic and had no noticeable deformity.

Two main types of TMSD have been described: type $\mathrm{I}$, in which the body of the sternum is displaced

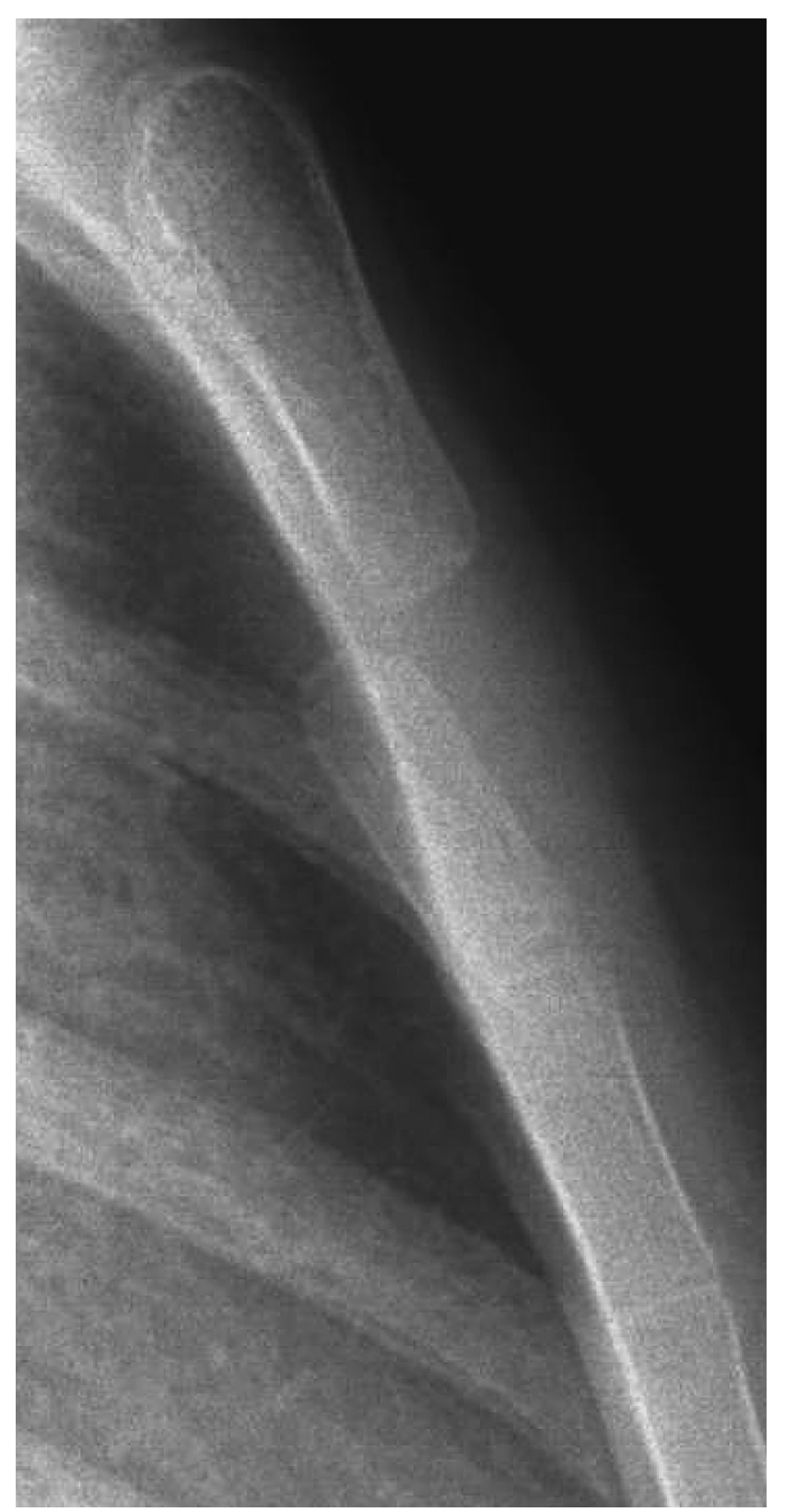

FIGURE 1. Lateral chest radiograph showing the manubriosternal joint dislocation (type 1 posterior dislocation of the sternal body). 
posteriorly as a result of direct compression injury to the anterior chest, and type II, in which the body of the sternum is anterior in relation to the manubrium and is caused by hyperflexion injury of the torso, occurring together with deceleration. The force is transmitted to the sternum through the clavicles, the chin, and the upper 2 ribs. ${ }^{4}$

We recommend operative immobilization of the joint (not necessarily anatomically perfect reduction) through a small incision as described above in symptomatic children with TMSD to relieve pain and prevent further deformity. The joint remodels itself in a growing child. Various operative procedures using plates, wire loops, Kirschner wires, or poly-p-dioxanone loops have been described in the literature. $^{3-5}$ We routinely use polypropylene for sternal closure after cardiac surgery. This may obviate some of the technical challenges and complications with the use of plates and wires, cosmetic concerns of larger incisions, and the need for a redo operation to remove the implant.

The authors acknowledge the services of Drs Provenzano, Singappuli, Justo, and Colen, and all the other medical and nursing staff involved in the care of our patient.

John Santosh Kumar Murala, MBBS, $M S, M C h$

Graham Nunn, MBBS (Hon), FRACS The Department of Pediatric Cardiac

Surgery
Mater Children's Hospital, Raymond

Terrace

South Brisbane, QLD, Australia

\section{References}

1. Irani AI, Lee TY, Estrera AL, Safi HJ. Repair of a traumatic sternal deformity. $J$ Thorac Cardiovasc Surg. 2008;136:1371-2.

2. Wada A, Fujii T, Takamura K, Yanagida H, Matsuura A, Katayama A. Sternal segment dislocation in children. J Pediatr Orthop. 2002;22:729-31.

3. Nijs S, Broos PLO. Sterno-manubrial dislocation in a 9-year old gymnast. Acta Chir Belg. 2005;105: 422-4.

4. Thirupathi R, Husted C. Traumatic disruption of the manubriosternal joint. Bull Hosp Jt Dis. 1982;42: 242-7.

5. Lemaitre J, Koriche CH, Massard G, Wihlm JM. Manubriosternal disjunction a new approach for surgical repair. Acta Chir Belg. 2004;104:593-5.

doi:10.1016/j.jtcvs.2009.01.029

\section{Reply to the Editor:}

We read with interest the letter by Dr Murala and associates ${ }^{1}$ on the repair of a manubriosternal fracture and would like to thank the authors for their comments regarding our recent publication on repair of traumatic sternal deformities. We also thank the editors for the opportunity to respond to the letter by Dr Murala and associates. We reported the possible morbid consequences of nonoperative management of sternal fractures when associated with multiple trauma. In our research of the subject, we also found multiple methods described for treatment of this entity, ranging from nonoperative "conservative" management to various open surgical methods. Richardson and colleagues in $1975^{2}$ described the concept of early operative repair for traumatic sternal deformities. $^{2}$ Our strategy has evolved over time and is now much more aggressive toward early surgical intervention. We currently favor the concept of early surgical fixation, with or without bone grafting as necessary. The method of fixation depends on the particular clinical situation and may range from simple suture, as used by Dr Murala and associates, to rigid titanium plates and screws as we described. Our bias also favors anatomic correction of the deformity in distinction to Dr Murala's commentary. It is our belief that this aggressive approach will avoid the late complications of chronic nonunion of the sternum and the associated morbidities.

Adel Irani, $M D$

University of Texas Medical School Houston

Cardiothoracic and Vascular Surgery Houston, Tex

\section{References}

1. Murala JSK, Nunn G. Management of traumatic manubriosternal dislocation in children [letter]. $J$ Thorac Cardiovasc Surg. 2009;138:517-8.

2. Richardson JD, Grover FL, Trinkle JK. Early operative management of isolated sternal fracture. $J$ Trauma. 1975;15:156-8.

doi:10.1016/j.jtcvs.2009.04.033 